\title{
О ВЛИЯНИИ ЗАСОРЕННОСТИ ПОСЕВОВ ОЗИМОЙ ПШЕНИЦЫ НА ИХ СПЕКТРАЛЬНУЮ ОТРАЖАТЕЛЬНУЮ СПОСОБНОСТЬ*
}

\author{
И.Ю. САВИН ${ }^{1,}$, Е.А. ШИШКОНАКОВАํㅛ, Е.Ю. ПРУДНИКОВА ${ }^{1,2}$, \\ Г.В. ВИНДЕКЕР1, П.Г. ГРУБИНА', Д.В. ШАРЫЧЕВ1, В.Н. ЩЕПОТЬЕВ1, \\ Ю.И. ВЕРНЮК 1,2 , А.В. ЖОГОЛЕВ 1
}

К малоизученным факторам, влияющим на спектральную отражательную способность посевов и, соответственно, успешность детектирования их состояния по данным дистанционного зондирования, относится засоренность посевов. На основе результатов полевых обследований проведен анализ влияния засоренности посевов озимой пшеницы в разные фазы вегетации на их спектральную отражательную способность (СОС) на примере нескольких полей в Тульской области с черноземами, серыми лесными и аллювиальными пахотными почвами. В полевых условиях несколько раз в течение сезона вегетации оценивалась засоренность посевов, определялась спектральная отражательная способность посевов, сорняков, листьев озимой пшеницы и почвы с использованием полевого спектрорадиометра FieldSpec ${ }^{\circledR}$ HandHeld $2^{\mathrm{TM}}$ («ASD, Inc.», CША), a также проводилось фотографирование поверхности посевов. Дешифрование полученных фотографий показало, что проективное покрытие сорняков на поверхности посевов достаточно низкое в начале и середине сезона вегетации пшеницы, но значительно возрастает с момента начала ее пожелтения. При этом проективное покрытие сорной растительности на поле с черноземами оказалось минимальным в начале и середине сезона вегетации и максимальным - к ее окончанию. Проективное покрытие на полях с серыми лесными и аллювиальными пахотными почвами статистически не различалось, но на аллювиальных почвах оно значимо возрастало к концу вегетации пшеницы. С использованием модели спектрального смешивания оценивался вклад засоренности в интегральное отражение света посевами в видимой и ближней инфракрасной областях спектра электромагнитных волн. Установлено, что, несмотря на достаточно высокую засоренность посевов озимой пшеницы в весенне-летний период, проективное покрытие сегетальных видов на поверхности посевов невелико. Его площадь слабо зависит от почвенных условий, а больше определяется другими факторами (историей полей, севооборотами и т.п.). Влияние сорной растительности на спектральную отражательную способность посевов изменяется во времени. Оно минимально на пике сезона вегетации, составляя несколько процентов для всех длин волн видимого и ближнего ИК диапазона. В начале послезимнего периода вклад сорной растительности в СОС посевов может достигать 10-20 \%, а в конце сезона сорная растительность предопределяет спектральный облик посевов на большинстве длин волн рассматриваемого диапазона. Наиболыший вклад наблюдается во всех случаях в ближней ИК $(\lambda=710-730$ нм $)$ и в зеленой $(\lambda=520-560$ нм $)$ областях спектра, но также есть периоды локальных максимумов вклада в синей области спектра $(\lambda=400-420$ нм). Представленные данные открывают возможность для разработки таких вегетационных индексов для дистанционного мониторинга посевов, которые позволят учитывать влияние засоренности лучше, чем при использовании традиционных индексов (например, NDVI Normalized Difference Vegetation Index). Кроме того, могут быть предложены специальные вегетационные индексы для дистанционного детектирования засоренности посевов озимой пшеницы.

Ключевые слова: спектральная отражательная способность, Тульская область, засоренность посевов, озимая пшеница, дистанционный мониторинг посевов.

Важное звено агрометеорологического обслуживания растениеводства - мониторинг состояния посевов. Его результаты используются при планировании агротехнологических операций, для расчета необходимого количества удобрений и прогнозирования урожайности сельскохозяйственных культур (1). Традиционно мониторинг состояния посевов осуществляется на учетных площадках в полевых условиях по специально разработанным инструкциям (2). Такие подходы трудоемки, их невозможно осуществить оперативно на больших площадях с хорошей точностью. Поэтому в последние десятилетия для мониторинга посевов все шире применяют дистанционное зондирование - с использованием как спутниковых систем, так и беспилотных летательных аппаратов. На основе данных

\footnotetext{
* Исследования проведены при финансовой поддержке РФФИ (грант № 18-016-00052) и гранта Минобрнауки России (соглашение № 05.607.21.0302).
} 
дистанционного зондирования решают задачи определения площадей посевов $(3,4)$, оценки их состояния $(5-7)$, прогнозирования урожайности $(8-$ 10), оценки почвенного плодородия (11). Эти подходы лишены недостатков традиционных методов, но они до сих пор недостаточно разработаны. Это связано как со спецификой самих данных дистанционного зондирования (их генерализованностью, необходимостью предварительной технической подготовки для анализа, значительной зависимостью информативности от даты съемки), так и спецификой самого объекта мониторинга посевов сельскохозяйственных культур (слабой изученностью их спектральной отражательной способности и ее изменчивости под влиянием тех или иных факторов) (12).

K малоизученным факторам, влияющим на спектральную отражательную способность посевов и, соответственно, успешность детектирования их состояния по данным дистанционного зондирования, относится засоренность посевов $(13,14)$. Засоренность посевов наиболее значимо проявляется при низком уровне агротехники и недостатке средств у землевладельцев на приобретение агрохимикатов для борьбы с сорными растениями. На территории бывшего СССР более 65 \% посевов сельскохозяйственных культур засорены в средней и сильной степени, что предопределяет значительные потери урожайности (15), которые, по данным Минсельхоза России достигают 30-40 \%. Характер и степень засоренности посевов, фенология сорняков на фоне фенологического развития культурных растений значительно варьирует от сезона к сезону. Это связано с особенностями метеорологических условий года, типа севооборота возделываемых культур, почвенных условий, агротехники $(16,17)$.

Вопросы влияния засоренности посевов на их спектральный облик до сих пор изучены недостаточно. Такие исследования ведутся, но в основном в связи с развитием подходов точного земледелия и локализации применения средств борьбы с сорной растительностью (18-20). Однако в этих исследованиях не идет речь о дистанционном распознавании видов сорной растительности, так как более важное практическое значение имеет точность определения площадей ее распространенности, а виды сорной растительности определяют непосредственно в поле. Работы по изучению спектральной отражательной способности у разных видов сорняков и ее динамики в течение сезона вегетации до сих пор очень немногочисленны (21-23).

В предлагаемой статье мы впервые показали, какова специфика влияния засоренности на спектральную отражательную способность посевов озимой пшеницы с учетом стадии ее развития и почвенного фона.

Целью наших исследований был анализ полевых данных о спектральной отражательной способности посевов и ее изменений в течение сезона вегетации на примере тестовых полей с озимой пшеницей в Тульской области России.

Методика. Исследования проводили в течение апреля-сентября 2018 года на 3 тестовых полях с посевами озимой пшеницы (сорт Московская 39) в Ясногорском и Щекинском районах Тульской области. Были выбраны поля с контрастными почвами (с учетом преобладающих): на 1-м поле доминировали серые лесные пахотные почвы, на 2-м - пахотные аллювиальные почвы, на 3-м - пахотные черноземы оподзоленные. Предзимний период вегетации озимой пшеницы на обследованных полях продолжался с начала октября до середины ноября, сход снежного покрова наблюдался в последней декаде марта, уборку урожая проводили в I декаде августа. На всех полях средства борьбы с сорной растительностью в сезон 
исследований не применяли.

На каждом поле на фоновых почвах закладывали тестовые площадки размером $4 \times 4$ м (число площадок на каждом поле указано в таблицах ниже), на которых проводили описание засоренности посевов в разные фенологические фазы пшеницы. С апреля по сентябрь произвели по 3 обследования на полях с серыми лесными и аллювиальными почвами (27 апреля, 1 июня, 6 июля) и 4 - на поле с черноземами (20 апреля, 25 мая, 29 июня, 17 августа). Всего в разные сроки на тестовых площадках выполнили 95 описаний растительности. Определяли общее проективное покрытие всех видов, общее проективное покрытие травяного и мохового ярусов, удельное проективное покрытие (для сегетальных видов), засоренность посевов в баллах по А.И. Мальцеву (24), видовой состав, аспект и аспектирующие виды, для каждого вида определяли высоту растений (преобладаюшую), ярусность по В.В. Алехину (25), обилие/покрытие по БраунБланке (26), при выраженном снижении жизненности учитывали этот показатель. Фенофазы описывали с учетом различия жизненных форм и систематических групп по стандартным методикам (27) отдельно для растущих на площадках травянистых растений (однолетних и многолетних), а также для хвощей и злаков. Фенофазы пшеницы определяли также по шкале ВВСН (28). В камеральных условиях рассчитывали встречаемость видов, систематизировали их по группам (однолетние/малолетние, многолетние корневищные, многолетние корнеотпрысковые и т.д.).

Одновременно с описанием посевы фотографировали в 5 повторностях с высоты 1,5 м, используя фотокамеру Nikon-D300s (Япония) с широкоформатным объективом. В это же время в 5-кратной повторности измеряли спектральную отражательную способность (СОС) поверхности посевов, листьев озимой пшеницы, выходящих на поверхность посева, и сорняков, выходящих на поверхность посева (все с высоты 1 м над поверхностью), а также открытой поверхности почвы (с высоты 15-20 см) с помощью спектрорадиометра FieldSpec ${ }^{\circledR}$ HandHeld $2^{\text {тм }}$ («ASD, Inc.», CША), позволяющего получать спектры отражения в диапазоне длин волн от 300 до 1025 нм с интервалом 2 нм. Перед анализом спектральные кривые сглаживали, применяя фильтр Савицкого-Голея (29) в программном пакете $\mathrm{R}$, и осредняли.

По широкоформатным фотографиям с использованием программы CAN-EYE (https://www6.paca.inrae.fr/can-eye/) определяли проективное покрытие посевов в целом (30), также осуществляли визуальное дешифрирование видимых на поверхности посевов листьев сорняков и измеряли их проективное покрытие. Проективное покрытие рассчитывали как относительную площадь объектов (листьев озимой пшеницы, листьев сорняков или открытой поверхности почв), изображенных на фотографиях поверхности посевов, полученных в надир. При дешифрировании применяли пакет программ ILWIS v.3.3 (https://www.itc.nl/ilwis/download/ilwis33/).

Спектральную отражательную способность поверхности посевов рассматривали как спектральную смесь отражений листьев озимой пшеницы, почвы и листьев сорняков. Согласно модели линейной спектральной смеси, вклад каждого объекта определяется долей этого объекта в смеси: $\mathrm{COC}_{\mathrm{c}}=\mathrm{S}_{1} \times \mathrm{COC}_{\mathrm{s}}+\mathrm{S}_{2} \times \mathrm{COC}_{\mathrm{ww}}+\mathrm{S}_{3} \times \mathrm{COC}_{\text {wе }}$, где $\mathrm{S}_{1}, \mathrm{~S}_{2}, \mathrm{~S}_{3}-$ относительные площади, занимаемые соответствующими классами (доли

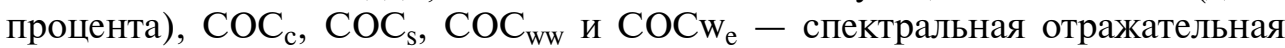
способность соответственно посевов, почв, листьев пшеницы и листьев сорняков. При этом размер влияния каждого из объектов, формирующих спектральную смесь, обусловлен относительной площадью, занимаемой 
каждым конкретным объектом на изображении поверхности посевов, и спектральными свойствами объекта. Таким образом, если принять интегральное отражение посевов за единицу, то можно оценить вклад сорняков и других компонентов спектральной смеси в общую СОС. Качество моделирования СОС посевов посредством линейного спектрального разложения оценивалось коэффициентом детерминации $\mathrm{R}^{2}$ между результатами моделирования и полевыми измерениями.

С помощью описанного подхода оценивали, насколько результаты моделирования СОС посевов на основе СОС пшеницы, сорняков и почвы отличаются от измеренных значений. После этого с учетом точности моделирования определяли вклад сорняков в формирование интегральной СОС посевов для всех участков и сроков наблюдений.

Статистическую обработку данных - расчет средних значений, доверительных интервалов, оценку статистической значимости различий $\left(t_{0,05}\right)$, предварительную обработку кривых спектрального отражения (их сглаживание и удаление выбросов) проводили с использованием пакетов stats и prospectr в среде R (https://www.r-project.org/).

Результаты. СОС измеряли для листьев пшеницы и сорняков, которые выходили на поверхность посева. В случае сорняков определяли СОС только у смеси доминирующих на поверхности посева видов и не учитывали этот показатель для видов, находящихся под пологом пшеницы. Таким образом, измерения велись лишь для тех растений, которые могли повлиять на СОС посевов в конкретную дату.

Агрофитоценозы поля с преобладанием серых лесных почв характеризовались высоким $\gamma$-разнообразием растительности. По итогам трех обследований выявили один кустарник и 49 видов сегетальных трав (из них 25 многолетников, 24 однолетника и малолетника) (табл. 1).

1. $\gamma$-Разнообразие растительности в агрофитоценозе озимой пшеницы сорта Московская 39 на поле с преобладанием серых лесных почв (Тульская обл., Ясногорский р-н, 2018 год)

\begin{tabular}{|c|c|c|c|}
\hline \multirow{2}{*}{ Показатель } & \multicolumn{3}{|c|}{ Дата обследования } \\
\hline & 27 апреля & 1 июня & 6 июля \\
\hline Число обследованных площадок & 14 & 10 & 10 \\
\hline Фенофаза пшеницы по Бейдеман (27) & вегетативная-кущение & $\begin{array}{l}\text { вегетативная- } \\
\text { выход в трубку }\end{array}$ & молочная спелость \\
\hline Фенофаза пшеницы по шкале ВВСН (28) & ВBCH 23 & BBCH 43 & BВCH 77 \\
\hline $\begin{array}{l}\text { Число видов на площадках, min-max (среднее): } \\
\text { сегетальные травы } \\
\text { однолетние виды } \\
\text { многолетние виды }\end{array}$ & $\begin{array}{l}6-13(8,5) \\
4-8(6,1) \\
1-7(2,4)\end{array}$ & $\begin{array}{c}15-26(18,6) \\
7-12(9,7) \\
6-14(8,9)\end{array}$ & $\begin{array}{r}19-26(22,4) \\
9-13(11,4) \\
8-14(11,0)\end{array}$ \\
\hline
\end{tabular}

За период наблюдения отмечали рост видового разнообразия: к началу июня - более чем в 2,0 раза, июля - в 2,5 раза по сравнению с началом вегетационного периода. При этом произошло некоторое снижение доли однолетних и малолетних трав. Если в апреле на площадках они образовывали основное покрытие и их доля значительно превышала половину от числа зафиксированных видов, то к июню-августу за счет активизации роста многолетних трав доля однолетних и малолетних снизилась до половины.

В апреле главную роль среди сорной растительности играли эфемеры и однолетние/малолетние сорные травы, имеющие зимующие формы: Capsella bursa-pastoris (L.) Medik., Consolida regalis S.F. Gray, Galium aparine L., Thlaspi arvense L., Tripleurospermum inodorum (L.) Sch. Bip., Viola arvensis Murr.) (здесь и далее названия растений приводятся по Маевскому) (31). B начале июня эфемеры отцветали и плодоносили, зимующие однолетни- 
ки/малолетники переходили к полному цветению и началу плодоношения. К ним в фазе проростков и вегетативных фаз, предшествующих бутонизации, а также в фазе бутонизации присоединились яровые однолетники (Chenopodium album L., виды рода Galeopsis L. и др.) и многолетники. Наибольшее значение для формирования проективного покрытия и аспекта сообществ поля в этот период играли корнеотпрысковые виды Equisetum arvense L. и Convolvulus arvensis L., а также Consolida regalis. К началу июля эфемеры, как и зимующие формы малолетников, завершили плодоношение, на многих площадках появились ранее не отмеченные однолетние травы - Erigeron canadensis L., Fallopia convolvulus (L.) Á. Löve, Spergularia rubra (L.) J. et C. Presl, возросло число экземпляров малолетних видов Picris hieracioides L., Cerastium holosteoides Fr., Myosotis arvensis (L.) Hill, появились новые многолетние виды - Achillea millefolium L., Galium mollugo L., Tanacetum vulgare L., Trifolium repens L., зеленые мхи. Наибольшую встречаемость отмечали у видов, присутствовавших на подавляющем числе площадок на протяжении всего периода наблюдений и составивших основное ядро этого агрофитоценоза: Arabidopsis thaliana (L.) Heynh. (97,0 \%), Consolida regalis $(91,2 \%)$, Tripleurospermum inodorum $(91,2 \%)$, Viola arvensis $(82,4 \%)$, Capsella bursa-pastoris $(79,4 \%)$, Potentilla argentea L. (73,5\%), Myosotis micrantha Pall. (70,6 \%), Poa compressa L. (70,6 \%), Scleranthus annuus L. (67,6 \%), Thlaspi arvense (64,7\%), Vicea tetrasperma (L.) Schreb. (58,8\%). Kpoме них важно отметить виды, характеризующиеся высокой встречаемостью только в летний период - Convolvulus arvensis (50,1 \%), Equisetum arvense (55,9\%), Hypericum perforatum L. (58,5\%).

B агрофитоценозе поля с преобладанием аллювиальных пахотных почв $\gamma$-разнообразие растительности было высоким (41 вид сегетальных трав, из них 20 многолетников, 21 однолетник и малолетник) (табл. 2).

2. $\gamma$-Разнообразие растительности в агрофитоценозе озимой пшеницы сорта Московская 39 на поле с преобладанием аллювиальных пахотных почв (Тульская обл., Ясногорский р-н, 2018 год)

\begin{tabular}{l|c|c|c}
\hline \multirow{2}{*}{ Показатель } & \multicolumn{3}{c}{ Дата обследования } \\
\cline { 2 - 4 } Число обследованных площадок & 27 апреля & 1 июня & 6 июля \\
Фенофаза пшеницы по Бейдеман (27) & 8 & 5 & 4 \\
Фенофаза пшеницы по шкале ВВСН (28) & вегетативная-кущение & $\begin{array}{c}\text { вегетативная- } \\
\text { выход в трубку молочная спелость }\end{array}$ \\
Число видов на площадках, min-max (среднее): & ВВСН 23 & ВВСН 44 & ВВСН 77 \\
$\quad$ сегетальные травы & $4-12(8,1)$ & $10-19(14,0)$ & $11-18(14,0)$ \\
однолетние виды & $3-7(4,4)$ & $6-11(8,2)$ & $7-12(8,7)$ \\
многолетние виды & $0-10(3,7)$ & $3-8(5,8)$ & $4-7(5,3)$ \\
\hline
\end{tabular}

За период наблюдения видовое разнообразие возрастало (см. табл. 2). В апреле в посевах зафиксировали меньшее присутствие однолетних и малолетних трав, чем на поле с серыми лесными почвами, что можно объяснить большей влажностью и меньшей температурой почвы, а также тем, что обследуемое поле только в 2017 году было вовлечено в сельскохозяйственный оборот после залежи, что, видимо, снизило возможность заносов однолетних и малолетних сорных видов. Несмотря на сравнительно высокое видовое разнообразие, для этого поля была характерна более низкая засоренность, чем для участка на серых лесных почвах. В летние месяцы развитию сорных трав препятствовала высокая сомкнутость пшеницы. Сорняки 3-го и 4-го ярусов вытягивались из-за нехватки света и запаздывали с прохождением фенологических фаз.

В апреле доминировали однолетние/малолетние сорняки, имеющие зимующие формы (Capsella bursa-pastoris, Galium aparine, Sisymbrium loeselii 
L., Tripleurospermum inodorum, Viola arvensis), а также всходы ранее распространенных на этом участке многолетних видов (Artemisia campestris L., Potentilla argentea, Vicea cracca L.). C началом летнего периода появлялись яровые однолетние виды Chenopodium album, Galeopsis speciosa Mill., Erigeron canadensis, Vicea tetrasperma, розетки двулетника Carduus crispus L., происходило массовое развитие корнеотпрыскового Convolvulus arvensis. Наибольшую встречаемость отмечали у Galium aparine (88,2 \%), Artemisia campestris (76,4\%), Capsella bursa-pastoris (70,6 \%), Sisymbrium loeselii $(58,8 \%)$, с начала июня она возрастала у Chenopodium album (47,1 \%), Convolvulus arvensis (47,1 \%), Vicea tetrasperma (41,2 \%), Erigeron canadensis $(35,3 \%)$, Galeopsis speciosa $(35,3 \%)$.

На черноземных почвах $\gamma$-разнообразие сегетальной растительности тестового поля также было сравнительно высоким: 44 вида трав, из них 15 многолетников, 29 однолетников и малолетников (табл. 3). Рост видового разнообразия наблюдали в мае и августе, в наиболее благоприятные по соотношению тепла и увлажнения почвы месяцы. В апреле доминировали зимующие формы однолетних сорняков (Capsella bursa-pastoris, Galium aparine, Viola arvensis), сравнительно часто встречались зимующие однолетники Raphanus raphanistrum L., Thlaspi arvense и эфемер Stellaria media (L.) Vill. B июне иссушение почвы привело к выпадению из травостоя ряда видов (Chenopodium album, Galeopsis sp., Fumaria officinalis L.). Август был отмечен развитием яровых форм Capsella bursa-pastoris, Fumaria officinalis, Viola arvensis, а также появлением поздних яровых однолетников Echinochloa crus-galli (L.) Beauv., Fallopia convolvulus, Chaenorrhinum minus (L.) Lange, Setaria glauca (L.) Beauv., Solanum nigrum L., Sonchus asper (L.) Hill. Встречаемость однолетнего вида Erigeron canadensis, как и многолетних стержнекорневых видов Artemisia vulgaris (L.), Cirsium arvense (L.) Scop., значительно увеличилась ко второй половине лета. Sonchus arvensis L. показал довольно высокую встречаемость в летние месяцы. Наиболее частыми были виды, присутствовавшие на подавляющем числе площадок на протяжении всего периода наблюдений - Galium aparine $(97,7$ \%), Viola arvensis $(95,5 \%)$, Capsella bursa-pastoris (77,2 \%).

3. $\gamma$-Разнообразие растительности в агрофитоценозе озимой пшеницы сорта Московская 39 на поле с преобладанием черноземных почв (Тульская обл., Щекинский р-н, 2018 год)

\begin{tabular}{|c|c|c|c|c|}
\hline \multirow{2}{*}{ Показатель } & \multicolumn{4}{|c|}{ Дата обследования } \\
\hline & 20 апреля & 25 мая & 29 июня & 17 августа \\
\hline Число обследованных площадок & 14 & 13 & 9 & 8 \\
\hline Фенофаза пшеницы по Бейдеман (27) & $\begin{array}{l}\text { вегетативная- } \\
\text { кущение }\end{array}$ & $\begin{array}{l}\text { вегетативная- } \\
\text { выход в трубку }\end{array}$ & $\begin{array}{l}\text { молочная } \\
\text { спелость }\end{array}$ & стерня \\
\hline Фенофаза пшеницы по шкале ВВСН (28) & BBCH 23 & BBCH 32 & BВCH 73 & ВВСН 99 \\
\hline $\begin{array}{l}\text { Число видов на площадках, min-max (среднее): } \\
\text { сегетальные травы }\end{array}$ & $3-6(4,7)$ & $5-14(8,5)$ & $3-11(5,8)$ & $8-19(12,6)$ \\
\hline однолетние виды & $2-5(4,0)$ & $4-10(6,9)$ & $2-8(4,4)$ & $6-12(8,6)$ \\
\hline многолетние виды & $0-1(0,7)$ & $0-5(1,6)$ & $0-3(1,4)$ & $1-7(4,0)$ \\
\hline
\end{tabular}

В таблице 4 приведены результаты дешифрирования проективного покрытия посевов по фотографиям, полученным в поле, осредненные для каждого тестового поля с разными преобладающими почвами. Необходимо отметить, что в геоботанике показатель «проективное покрытие» определяет относительную площадь проекции отдельных видов или их групп, ярусов и т.д. фитоценоза на поверхность почвы. В настоящей статье под этим термином мы подразумеваем относительную площадь объектов (листьев озимой пшеницы, листьев сорняков или открытой поверхности почв), изображен- 
ных на фотографиях поверхности посевов, полученных в надир.

4. Проективное покрытие на поверхности посевов озимой пшеницы (\%) сорта Московская 39 на полях с разным типом почв (Тульская обл., Ясногорский и Щекинский районы, 2018 год)

\begin{tabular}{l|c|c|c|c|c}
\hline \multicolumn{1}{c|}{ Тип почв } & $\begin{array}{l}\text { Дата обсле- } \\
\text { дования }\end{array}$ & $\begin{array}{l}\text { Число } \\
\text { площадок }\end{array}$ & Пшеница & Сорняки & Почва \\
\hline Черноземы & 20.04 .2018 & 5 & $17,5 \pm 4,6$ & $0,2 \pm 0,1$ & $82,5 \pm 9,9$ \\
Серые лесные & 26.04 .2018 & 14 & $22,0 \pm 2,7$ & $5,9 \pm 1,7$ & $72,6 \pm 2,7$ \\
Аллювиальные & 26.04 .2018 & 8 & $38,5 \pm 5,5$ & $5,6 \pm 2,6$ & $55,9 \pm 4,6$ \\
Черноземы & 26.05 .2018 & 13 & $93,9 \pm 1,6$ & $0,5 \pm 0,1$ & $5,6 \pm 1,6$ \\
Серые лесные & 01.06 .2018 & 10 & $69,1 \pm 6,3$ & $2,9 \pm 0,1$ & $28,0 \pm 6,2$ \\
Аллювиальные & 01.06 .2018 & 4 & $83,6 \pm 2,0$ & $2,9 \pm 0,1$ & $13,5 \pm 1,8$ \\
Черноземы & 29.06 .2018 & 9 & $62,3 \pm 2,6$ & $0,2 \pm 0,1$ & $37,5 \pm 2,6$ \\
Серые лесные & 06.07 .2018 & 10 & $69,0 \pm 2,9$ & $6,4 \pm 2,5$ & $24,6 \pm 2,4$ \\
Аллювиальные & 06.07 .2018 & 4 & $60,3 \pm 15,0$ & $14,6 \pm 11,9$ & $25,1 \pm 3,8$ \\
Черноземы & 18.08 .2018 & 8 & $28,4 \pm 9,5$ & $25,4 \pm 12,1$ & $46,2 \pm 7,2$ \\
Пр и м е ч н и е. Доверительные интервалы $M \pm\left(t_{0,05} \times \mathrm{SEM}\right)$ не превышают $\pm 5 \%$. & \\
\hline
\end{tabular}

Дешифрование показало, что проективное покрытие сорняков на поверхности посевов достаточно низкое в начале и середине сезона вегетации пшеницы, но значительно возрастает с момента начала ее пожелтения. При этом проективное покрытие сорной растительности на поле с черноземами оказалось минимальным в начале и середине сезона вегетации и максимальным - к ее окончанию. Проективное покрытие на полях с серыми лесными и аллювиальными пахотными почвами достоверно не различалось $(\mathrm{p}>0,05)$, но на аллювиальных почвах оно существенно увеличивалось к концу вегетации пшеницы (различия между сроками наблюдений статистически значимы, $\mathrm{p} \leq 0,05)$.

СОС сорняков отличается от СОС листьев пшеницы (рис. 1). Эти различия были особенно заметными в инфракрасной (ИК) и красной областях спектра. Интересно также отметить, что в разные фенофазы общая форма кривой СОС и закономерности отражения света оказались схожи. Но характер отражения в ИК и красной областях спектра при фенологическом развитии пшеницы и сорняков может меняться разнонаправленно. Так, в примере, приведенном на рисунке 1, листья пшеницы в более зрелом состоянии отражали меньше солнечной энергии (особенно в ИК области), а сорная растительность, наоборот, больше. При этом у сорняков (в отличие от пшеницы) разница в СОС в зависимости от даты наблюдения в большей степени зависела не от фазы их развития, а от смены видового состава сорной растительности, экспонирующейся на поверхности посевов в течение вегетационного сезона. Но даже при этом величина СОС листьев сорной растительности, выходящей на поверхность посева, между собой оказалась очень схожей (различия статистически незначимы, р > 0,05).

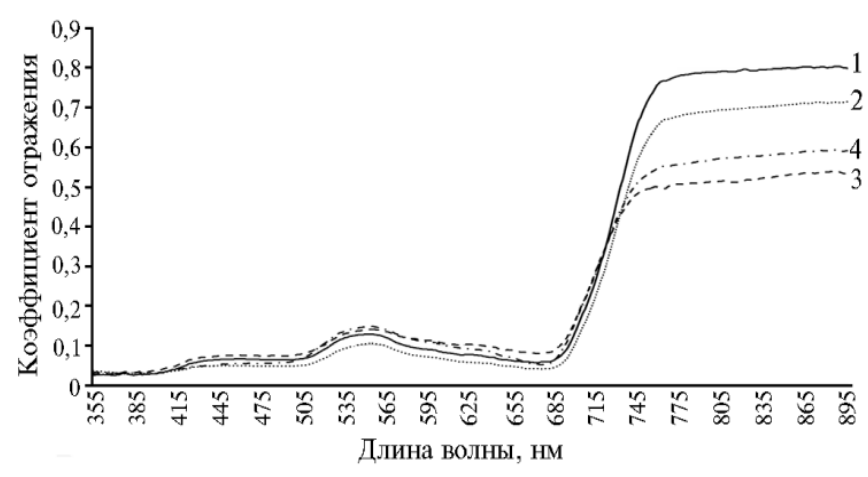

Рис. 1. Примеры кривых спектрального отражения листьев озимой пшеницы сорта Московская 39 и сорной растительности для двух сроков обследования на поле с серыми лесными почвами: 1 - пшеница (26.04), 2 - пшеница (01.06), 3 - сорняки (26.04), 4 - сорняки (01.06) (Тульская обл., Ясногорский р-н, 2018 год; спектрорадиометр Field-Spec ${ }^{\circledR} \quad$ HandHeld $2^{\mathrm{TM}}$, «ASD, Inc.», США).

Моделирование интегральной СОС по СОС компонентов спектральной смеси показало, 
что в целом результаты вполне адекватно отражают реальные измерения СОС посевов. Полученные данные представлены в обобщенном виде на рисунке 2.

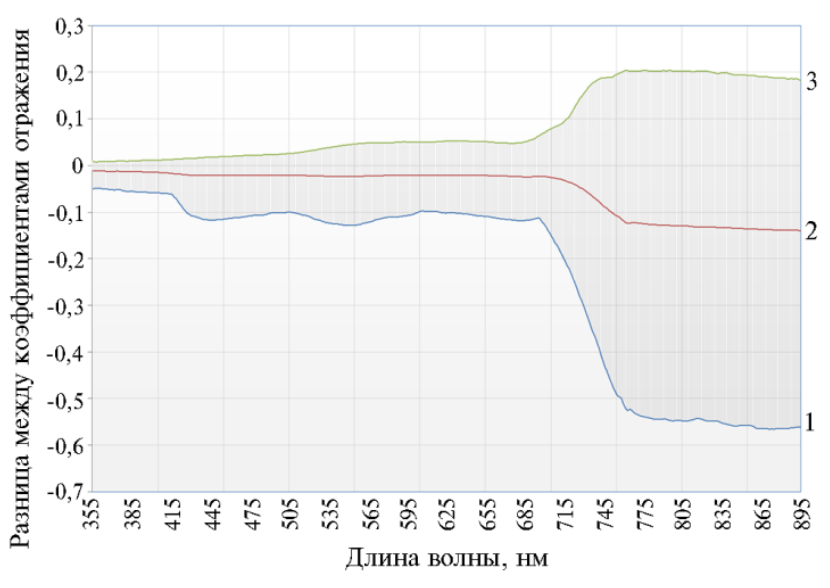

Рис. 2. Минимальная (1), средняя (2) и максимальная (3) разница между величинами коэффициентов отражения, полученными при измерении светоотражающей способности посевов (пшеница сорта Московская 39) в поле и моделировании по методу линейной спектральной смеси, для каждой длины волны для всех измерений (Тульская обл., Ясногорский и Щекинский районы, 2018 год).

Разница между результатами моделирования СОС и ее измерениями в поле была низ-

кой для видимого диапазона спектра (при $\lambda$ от 350 до 700 нм), но возрастала для инфракрасного диапазона ( $\lambda=700-900$ нм). В видимом диапазоне она не превышает 0,1 величины коэффициента отражения, тогда как в ИК диапазоне для отдельных точек может достигать 0,5-0,6 (см. рис. 2). Основная причина этого, вероятно, в том, что для оценки проективного покрытия использовались фотографии, полученные в видимом диапазоне спектра, которые не отражают неоднородности, характерные для ИК диапазона. Кроме того, на результат могли повлиять и погрешности в идентификации сорняков по широкоформатным фотографиям, и наличие (хотя и в небольших количествах) на фотографиях, полученных в начале и конце сезона вегетации, отмершей растительности (стерни или листьев деревьев ближайших лесополос).

Оценка, выполненная по результатам моделирования вклада сорной растительности в интегральную СОС посевов, показала следующее (рис. 3).

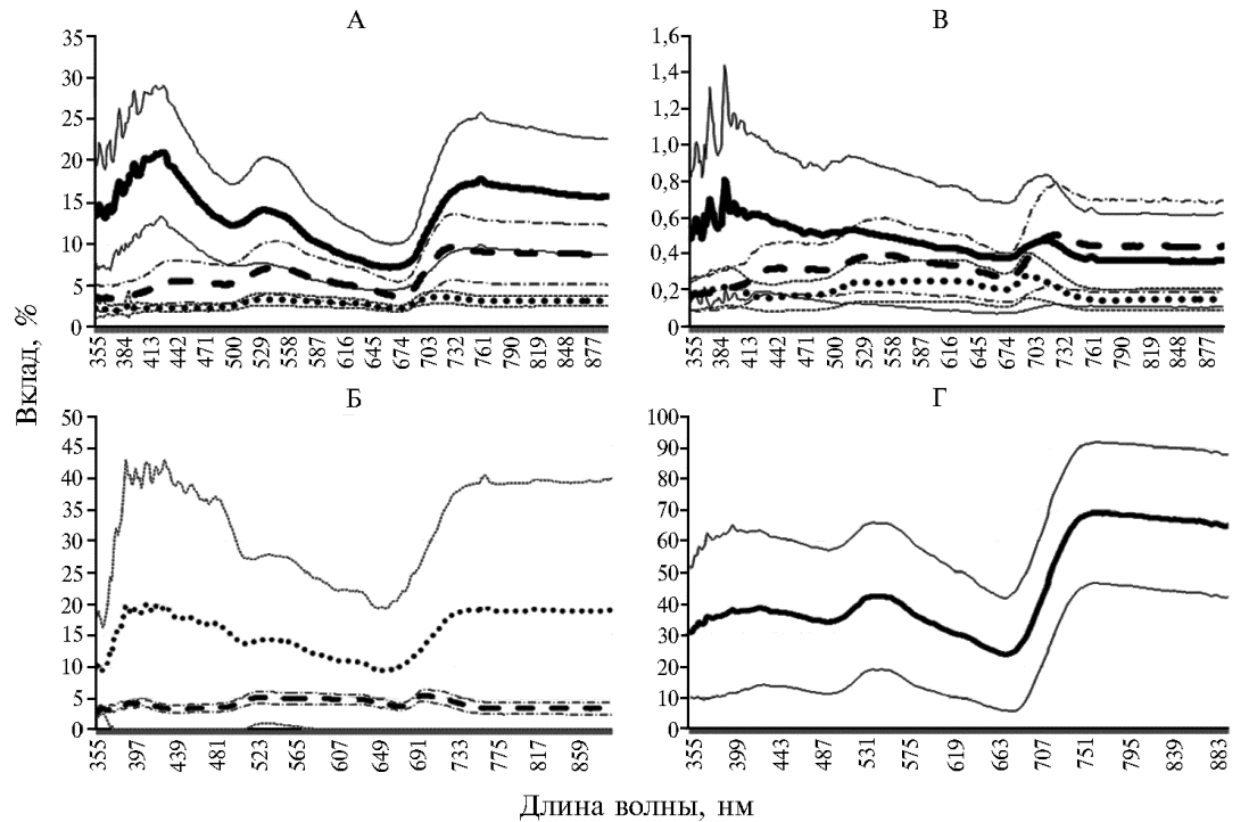

Рис. 3. Среднее значение $\left(M\right.$, жирные линии) и доверительные интервалы $\left(t_{0,05} \times \mathrm{SEM}\right.$, тонкие 
линии) для вклада сорной растительности в интегральную светоотражающую способность посевов пшеницы на серых лесных почвах по результатам моделирования (А, сплошные линии для даты 26.04.2018, пунктирные линии - для 01.06.2018, точечные линии - для 06.07.2018); на аллювиальных почвах (Б, пунктирные линии - для 01.06.2018, точечные - для 06.07.2018) и на черноземах (В, пунктирные линии - для 20.04.2018, точечные - для 26.05.2018, сплошные для 29.06.2018; Г - для 18.08.2018) (Тульская обл., Ясногорский и Щекинский районы).

Видно, что наибольший вклад сорной растительности в СОС посевов наблюдался весной в начале сезона вегетации, а также в конце вегетации. При этом в конце сезона вклад сорняков становился максимальным: на некоторых длинах волн после уборки урожая он близок к $100 \%$ (см. рис. 3, Г). В середине периода вегетации вклад сорной растительности был минимален на всех почвах и не превышал нескольких процентов. Наибольший вклад наблюдали во всех случаях в ближней ИК (710-730 нм) и в зеленой (520-560 нм) областях спектра, но в некоторые сроки локальные максимумы отмечали и в синей области (400-420 нм).

Таким образом, засоренность обследованных посевов озимой пшеницы в целом достаточно высокая. Она зависит как от типа почв, так, по-видимому, и от истории использования полей и севооборотов, что вполне соответствует закономерностям, установленным ранее (16). Но сорная растительность во многих случаях не выходит в верхний ярус агрофитоценоза, особенно при максимальном развитии надземной фитомассы пшеницы. Об этом наглядно свидетельствуют данные о проективном покрытии сорняков на поверхности посевов (см. табл. 4). В наибольшей степени сорная растительность выходит на поверхность посева в конце сезона вегетации и после уборки пшеницы, что в принципе подтверждает установленные ранее закономерности (32). Это связано с тем обстоятельством, что пожелтевшая пшеница в гораздо меньшей степени перехватывает влагу и питательные вещества, а также пропускает внутрь посевов больше света (33), что создает более благоприятные условия для развития сорной растительности.

Как уже указывалось выше, СОС сорняков статистически значимо (при $\mathrm{p} \leq 0,05)$ отличается от СОС пшеницы. Наибольшие различия наблюдаются в ИК и зеленой области спектра вследствие того, что сорная растительность имеет более зеленый цвет, чем листья пшеницы (особенно в начале послезимней вегетации и после прохождения максимума вегетации), что подтверждает данные, полученные исследователями ранее (19, 34). Меньшие, но в некоторых случаях достаточно заметные различия наблюдаются в красной области спектра, где сорная растительность немного сильнее отражает солнечную энергию в сравнении с листьями пшеницы из-за несколько большего содержания в ней влаги (35). Отмеченные вариации спектров сорной растительности в течение сезона вегетации связаны с тем, что изменяется как цвет листьев самих сорных растений, так и их присутствие в посевах, что подтверждает данные более ранних публикаций (13). Но эти модификации не носят кардинального характера: локальные экстремумы кривой отражения остаются на фиксированных длинах волн, изменяется лишь их абсолютная величина, но не намного. Так, изменение СОС сорной растительности, выходящей на поверхность посевов во все даты наших обследований на всех почвах и длинах волн, не превышало $5 \%$.

Необходимо отметить, что доля сорной растительности, которая выходит на поверхность посева, намного ниже, чем общая засоренность. Эта доля связана с преобладающими почвами, а также, по-видимому, с метеорологическими условиями сезона, спецификой агротехники возделывания культур на разных почвах, а также с типом предшественника (36). 
Наши обследования показали наименьший выход сорной растительности на поверхность посевов на черноземах, наибольшей - на пахотных аллювиальных почвах. Отметим, что проективное покрытие сегетальных видов в середине сезона вегетации на всех почвах за редким исключением не превышало нескольких процентов. При этом в начале сезона оно может достигать 10-20 \%, а в конце сезона и особенно сразу после уборки пшеницы доходит до 30-40 \%. Это связано с развитостью растений пшеницы и густотой посевов, а также с меньшей сомкнутостью посевов в начале вегетации, пожелтением листьев пшеницы после антезиса и фенологическим развитием самой сорной растительности.

Вследствие динамики СОС и проективного покрытия сорной растительности и пшеницы в течение сезона вегетации изменяется и вклад сегетальной растительности в интегральную СОС посевов. Качество моделирования СОС посевов посредством линейного спектрального разложения оказалось недостаточным для надежных количественных оценок в ИК зоне спектра (коэффициент детерминации $\mathrm{R}^{2}$ между результатами моделирования и полевыми измерениями в видимом диапазоне спектра оказался равен 0,83 , а для ближнего ИК диапазона - всего 0,54), но общая тенденция по ним прослеживается.

В целом закономерности вклада сорной растительности в СОС посевов на разных почвах схожи. В начале сезона вегетации вклад, как правило, минимален (от полного отсутствия засоренности до нескольких процентов), что отмечалось и ранее (14). В наших исследованиях он оказался ощутимым (до 20-30 \%) лишь на поле с серыми лесными почвами, что, скорее всего, связано с особенностями использования поля в предыдущий год. Следовательно, вклад сорняков в начале послезимнего периода вегетации, вероятно, предопределяется не почвенными условиями, а тем, как использовали поле в предыдущие годы. Этот вклад максимален в ближней ИК и зеленой областях спектра, что вполне ожидаемо для зеленой растительности.

По мере фенологического развития растений и смыкания посевов влияние сорной растительности на интегральную СОС посевов падает и не превышает нескольких процентов на всех длинах волн на всех почвах. Но в середине сезона вегетации на поле с аллювиальными почвами в одной точке также было зафиксировано повышенное влияние сорной растительности на СОС посевов (из-за обильного развития высокорослых сорняков, перекрывающих ярус пшеницы). Это свидетельствует о том, что вклад сорной растительности может и на пике сезона вегетации быть повышенным и статистически значимым, что связано, вероятно, со спецификой внутриполевого варьирования почвенных условий и применением мер борьбы с засоренностью на конкретных полях в прошлые годы.

В конце сезона вегетации пшеницы (начиная с момента пожелтения листьев) вклад сорной растительности в СОС посевов возрастает на всех почвах, достигая максимума после уборки урожая, когда сегетальные растения, находящиеся под пологом пшеницы, оказываются на поверхности. Подобные закономерности были выявлены ранее и для посевов ярового ячменя (32). В указанный период в ближнем ИК и зеленом диапазонах спектра отражение света формируется преимущественно сорной растительностью. Представляет интерес тот факт, что в это время сильно возрастает доля вклада сорной растительности в отражательную способность посевов озимой пшеницы в синей области спектра, где он часто начинает превышать вклад в ИК области спектра, чего не отмечали для ярового ячменя. 
Итак, проведенные исследования показали, что, несмотря на достаточно высокую засоренность посевов озимой пшеницы в весеннелетний период, проективное покрытие сорняков на поверхности посевов невелико. Величина проективного покрытия сорной растительности на поверхности посевов слабо зависит от почвенных условий, а больше определяется другими факторами (историей полей, севооборотами и т.п.). Влияние сорной растительности на спектральную отражательную способность посевов озимой пшеницы изменяется во времени. Оно минимально на пике сезона вегетации, составляя несколько процентов для всех длин волн видимого и ближнего ИК диапазона. В начале послезимнего периода вегетации вклад сорной растительности в СОС посевов может достигать 10-20\%, а в конце сезона вегетации сорная растительность предопределяет характеристики посевов на большинстве длин волн рассматриваемого диапазона. Во всех случаях наибольший вклад наблюдается в ближней ИК $(\lambda=710-730$ нм) и зеленой $(\lambda=520-560$ нм) областях спектра, но в некоторые сроки отмечаются локальные максимумы вклада и в синей области спектра ( $\lambda=400-420$ нм). Полученные нами данные открывают возможность для разработки таких вегетационных индексов для дистанционного мониторинга посевов, которые позволят учитывать влияние засоренности лучше традиционно используемых (например, NDVI - Normalized Difference Vegetation Index). Кроме того, могут быть предложены специальные вегетационные индексы для дистанционного детектирования засоренности посевов озимой пшеницы.

\footnotetext{
1ФГБНУ Почвенный институт им. В.В. Докучаева, 119017 Россия, г. Москва, Пыжевский пер., 7, стр. 2, e-mail: savin_iyu@esoil.ru $\bowtie$, shishkonakova_ea@esoil.ru, prudnikova_eyu@esoil.ru, vindeker_gv@esoil.ru, grubina_pg@esoil.ru, sharychev_dv@esoil.ru, schepotiev_vn@esoil.ru, verniuk_yui@esoil.ru, zhogolev_av@esoil.ru;

2 Аграрно-технологический институт

Российского университета дружбы народов,

117198 Россия г. Москва, ул. Миклухо-Маклая, 8, к. 2
}

Sel'skokhozyaistvennaya biologiya [Agricultural Biology], 2020, V. 55, № 1, pp. 53-65

Поступила в редакцию 12 декабря 2019 года

\title{
ABOUT EFFECT OF WEEDS ON SPECTRAL REFLECTANCE PROPERTIES OF WINTER WHEAT CANOPY
}

\author{
I.Yu. Savin1, 2, E.A. Shishkonakova1, E.Yu. Prudnikova1, 2, G.V. Vindeker', P.G. Grubina1, \\ D.V. Sharychev', V.N. Schepotiev', Yu.I. Verniuk ${ }^{1,2}$, A.V. Zhogolev' ${ }^{1}$
}

\begin{abstract}
${ }^{1}$ Dokuchaev Soil Science Institute, Pyzhyovskii per. 7/str. 2, Moscow, 119017 Russia, e-mail savin_iyu@esoil.ru ( $\square$ corresponding author), shishkonakova_ea@esoil.ru, prudnikova_eyu@esoil.ru, vindeker_gv@esoil.ru, grubina_pg@esoil.ru, sharychev_dv@esoil.ru, schepotiev_vn@esoil.ru, verniuk_yui@esoil.ru, zhogolev_av@esoil.ru;

${ }_{2}^{2}$ Agrarian and Technological Institute RUDN, ul. Miklukho-Maklaya 8/2, Moscow, 117198 Russia ORCID:

Savin I.Yu. orcid.org/0000-0002-8739-5441

Shishkonakova E.A. orcid.org/0000-0003-4396-2712

Prudnikova E.Yu. orcid.org/0000-0001-7743-8607

Vindeker G.V. orcid.org/0000-0002-0463-4241

Grubina P.G. orcid.org/0000-0001-6325-4604

The authors declare no conflict of interests

Acknowledgements:

Supported financially by Russian Foundation for Basic Research, grant No. 18-016-00052, and by Ministry of Science and Higher Education of the Russian Federation (agreement № 05.607.21.0302)

Received December 12, 2019

Sharychev D.V. orcid.org/0000-0002-6799-3209 Schepotiev V.N. orcid.org/0000-0002-6276-5637 Verniuk Yu.I. orcid.org/0000-0002-3621-8330 Zhogolev A.V. orcid.org/0000-0003-2225-7037

doi: 10.15389 /agrobiology.2020.1.53eng
\end{abstract}

\section{Abstract}

Among the poorly studied factors affecting the spectral reflectivity of crops and, consequently, the success of detection of their condition based on remote sensing data is crop weedness. On the basis of field survey data, the effect of weed infestation on winter wheat spectral reflectivity at 
different stages of vegetation was analyzed using the example of individual fields in the Tula region with chernozems, grey forest, and alluvial arable soils. Under field conditions, crop weedness, spectral reflectance of crops, weeds, winter wheat leaves and soil was determined using FieldSpec ${ }^{\circledR}$ HandHeld $2^{\mathrm{TM}}$ field spectro-radiometer (ASD, Inc., USA) was assessed several times during the growing season, and the crop surface was photographed. The decoding of the photos showed that the projective weed coverage on the crop surface is low enough at the beginning and middle of the wheat growing season, but increases significantly since the beginning of leaves yellowing. At the same time, the projective coverage of weeds in the field with chernozems was minimal at the beginning and middle of the growing season, and maximal - by the end of the growing season. Projective coverage of weeds on fields with grey forest and alluvial arable soils did not differ statistically, but on alluvial soils it increased significantly by the end of wheat vegetation. Using the spectral mixing model, the contribution of weeds infestation to the integral reflection of light by crops in the visible and near infrared bands of the electromagnetic waves was estimated. It has been found that despite the rather high weedness of winter wheat canopy in the spring-summer growing season, its projective coverage on the surface of the crop canopy is small. The magnitude of the projective cover of weeds on the surface of crop canopy weakly depends on soil conditions, and is more determined by other factors (history of fields use, crop rotation, etc.). The effect of weed vegetation on the spectral reflectivity of crops changes over time. It is minimal at the peak of the growing season, accounting for several percent for all wavelengths of the visible and near IR range. At the beginning of the post-winter vegetation period, the contribution of weed vegetation to the spectral reflectance of crops can reach 10$20 \%$, and at the end of the vegetation season, weed vegetation can predetermine the spectral appearance of crops at most wavelengths of the considered range. The greatest contribution is observed in all cases in the near IR $(710-730 \mathrm{~nm})$ and in the green $(520-560 \mathrm{~nm})$ spectral region, but at certain times there are local maxima of the contribution and in the blue spectral region of electromagnetic waves $(400-420 \mathrm{~nm})$. The data obtained open up the possibility for the development of new vegetation indices for remote monitoring of crops, which will be less affected by weedness than those traditionally used (for example, NDVI). Conversely, on the basis of the data obtained, special vegetation indices can be proposed for the remote detection of the weedness of winter wheat canopy.

Keywords: spectral reflectance, Tula region, crop weedness, winter wheat, remote sensing monitoring of crops.

\section{REFERENCES}

1. Razvitie sel'skokhozyaistvennoi meteorologii v Rossii. Pod redaktsiei I.G. Gringofa, A.D. Kleshchenko [Agricultural meteorology in Russia. I.G. Gringof, A.D. Kleshchenko (eds.)]. Obninsk, 2009 (in Russ.).

2. Gringof I.G., Fedorova Z.S., Belolyubtsev A.I., Malakhova S.D. Praktikum po agrometeorologii. Chast' I. Meteorologicheskie izmereniya i nablyudeniya. Chast' II. Agrometeorologicheskie izmereniya $i$ nablyudeniya [Workshop on agrometeorology. Part I. Meteorological measurements and observations. Part II Agrometeorological measurements and observations]. Obninsk, 2018 (in Russ.).

3. Ennouri K., Kallel A. Remote sensing: an advanced technique for crop condition assessment. Mathematical Problems in Engineering, 2019, 2019: Article ID 9404565 (doi: 10.1155/2019/9404565).

4. Tolpin V.A., Bartalev S.A., Efremov V.Yu., Lupyan E.A., Savin I.Yu., Flitman E.V. Sovremennye problemy distantsionnogo zondirovaniya Zemli iz kosmosa, 2010, 7(2): 221-232 (in Russ.).

5. Savin I.Yu., Nègre T. Agro-meteorological monitoring in Russia and Central Asian countries. Ispra, OPOCE, 2006.

6. Becker-Reshef I., Justice C., Sullivan M., Vermote E., Tucker C., Anyamba A., Small J., Pak E., Masuoka E., Schmaltz J., Hansen M., Pittman K., Birkett C., Williams D., Reynolds C., Doorn B. Monitoring global croplands with coarse resolution earth observations: the Global Agriculture Monitoring (GLAM) project. Remote Sensing, 2010, 2(6): 1589-1609 (doi: $10.3390 / \mathrm{rs} 2061589)$.

7. Wu B., Meng J., Li Q., Yan N., Du X., Zhang M. Remote sensing-based global crop monitoring: experiences with China's CropWatch system. International Journal of Digital Earth, 2014, 7(2): 113-137 (doi: 10.1080/17538947.2013.821185).

8. Savin I. Crop yield prediction with SPOT VGT in Mediterranean and Central Asian countries. In: ISPRS Archives XXXVI-8/W48 Workshop proceedings: Remote sensing support to crop yield forecast and area estimates. Commission VIII, WG VIII/10. OPOCE, Stresa, 2007: 130-134.

9. Rembold F., Atzberger C., Savin I., Rojas O. Using low resolution satellite imagery for yield prediction and yield anomaly detection. Remote Sensing, 2013, 5(4): 1704-1733 (doi: $10.3390 /$ rs5041704).

10. Bereza O.V., Strashnaya A.I., Lupyan E.A. Sovremennye problemy distantsionnogo zondirovaniya Zemli iz kosmosa, 2015, 12(1): 18-30 (in Russ.). 
11. Savin I.Yu., Vernyuk Yu.I., Faraslis I. Byulleten' Pochvennogo instituta im. V.V. Dokuchaeva, 2015, 80: 95-105 (doi: 10.19047/0136-1694-2015-80-95-105) (in Russ.).

12. Savin I.Yu. V sbornike: Primenenie sredstv distantsionnogo zondirovaniya zemli $v$ sel'skom khozyaistve [In: The use of remote sensing of land in agriculture]. St. Petersburg, 2015: 29-32 (in Russ.).

13. Menges R.M., Nixon P.R., Richardson A.J. Light reflectance and remote sensing of weeds in agronomic and horticultural crops. Weed Science, 1985, 33(4): 569-581 (doi: 10.1017/S0043174500082862).

14. Thorp K., Tian L.F. A review on remote sensing of weeds in agriculture. Precision Agriculture, 2004, 5(5): 477-508 (doi: 10.1007/s11119-004-5321-1).

15. Zakharenko V.A. Agrokhimiya, 1997, 3: 67-74 (in Russ.).

16. Petit S., Boursault A., Guilloux M., Munier-Jolain N., Reboud X. Weeds in agricultural landscapes. A review. Agronomy for Sustainable Development, 2011, 31(2): 309-317 (doi: 10.1051/agro/2010020).

17. Sineshchekov V.E., Vasil'eva N.V. Vestnik NGAU (Novosibirskii gosudarstvennyi agrarnyi universitet), 2017, 4: 32-40 (in Russ.).

18. Lamba D.W., Brown R.B. PA - precision agriculture: remote-sensing and mapping of weeds in crops. Journal of Agricultural Engineering Research, 2001, 78(2): 117-125 (doi: 10.1006/jaer.2000.0630).

19. Martin M. P., Barreto L., Riaco D., Fernandez-Quintanilla C., Vaughan P. Assessing the potential of hyperspectral remote sensing for the discrimination of grassweeds in winter cereal crops. International Journal of Remote Sensing, 2011, 32(1): 49-67 (doi: 10.1080/01431160903439874).

20. Pflanz M., Nordmeyer H., Schirrmann M. Weed mapping with UAS Imagery and a Bag of Visual Words based image classifier. Remote Sensing, 2018, 10(10): 1530 (doi: $10.3390 / \mathrm{rs} 10101530)$.

21. Noble S., Brown R., Crowe T. The use of spectral properties for weed detection and identification - a review. Presentation at the AIC 2002 Meeting CSAE/SCGR Program Saskatoon, Saskatchewan, July 14-17, 2002. Saskatoon, 2002: Paper No. 02-208.

22. Vrindts E.J. De Baerdemaeker J., De Baerdemaeker, Ramon H. Weed detection using canopy reflection. Precision Agriculture, 2002, 3(1): 63-80 (doi: 10.1023/A:1013326304427).

23. Che'Ya N., Gupta M., Doug G., Lisle A., Basnet B., Campbell G. Spectral discrimination of weeds using hyperspectral radiometry. Proceedings of the 5th Asian Conference on Precision Agriculture (ACPA), June 25-28, 2013, Jeju, Korea. Jeju, 2013: 325.

24. Mal'tsev A.I. Sornaya rastitel'nost' SSSR i mery bor'by s neyu [Weed vegetation and its combating in the USSR]. Leningrad, 1936 (in Russ.).

25. Alekhin V.V. Metodika polevogo izucheniya rastitel'nosti i flory [Methods of field study of vegetation and flora]. Moscow, 1938 (in Russ.).

26. Ponyatovskaya V.M. V knige: Polevaya geobotanika. Tom III. Pod redaktsiei E.M. Lavrenenko, A.A. Korchagina [In: Field geobotany. Vol. III. E.M. Lavrenenko, A.A. Korchagin (eds.)]. Moscow-Leningrad, 1964: 209-290 (in Russ.).

27. Beideman I.N. V knige: Polevaya geobotanika. Tom II. Pod redaktsiei E.M. Lavrenenko, A.A. Korchagina In: Field geobotany. Vol. II. E.M. Lavrenenko, A.A. Korchagin (eds.)]. MoscowLeningrad, 1960: 333-366 (in Russ.).

28. Growth stages of mono- and dicotyledonous plants. BBCH Monograph. U. Meier (ed.). Federal Biological Research Centre for Agriculture and Forestry 2001.

29. Savitzky A., Golay M.J.E. Smoothing and differentiation of data by simplified least squares procedures. Analytical Chemistry, 1964, 36(8): 1627-1239 (doi: 10.1021/ac60214a047).

30. Weiss M., Baret F., Myneni R.B., Pragnère A., Knyazikhin Y. Investigation of a model inversion technique to estimate canopy biophysical variables from spectral and directional reflectance data. Agronomie, 2000, 20(1): 3-22 (doi: 10.1051/agro:2000105).

31. Maevskii P.F. Flora srednei polosy evropeiskoi chasti Rossii [Flora of the middle zone of the European part of Russia]. Moscow, 2014 (in Russ.).

32. Savin I.Yu., Dokukin P.A., Vernyuk Yu.I., Zhogolev A.V. Sovremennye problemy distantsionnogo zondirovaniya Zemli iz kosmosa, 2017, 14(3): 185-195 (doi: 10.21046/2070-7401-2017-14-3-185195) (in Russ.).

33. Verstraete M.M. Radiation transfer in plant canopies - transmission of direct solar radiation and the role of leaf orientation. Journal of Geophysical Research, 1987, 92(D9): 10985-10995 (doi: 10.1029/JD092iD09p10985).

34. Merotto A. Jr., Bredemeier C., Vidal R.A., Goulart I.C.G.R., Bortoli E.D., Anderson N.L. Reflectance indices as a diagnostic tool for weed control performed by multipurpose equipment in precision agriculture. Planta Daninha, 2012, 30(2): 437-447 (doi: 10.1590/S010083582012000200024).

35. Abouziena H.F., El-Saeid H.M., Amin A.A.E. Water loss by weeds: a review. International Journal of Chem Tech Research, 2014, 7(01): 323-336.

36. Zimdahl R.L. Fundamentals of weed science. Elsevier Inc., 2018 (doi: 10.1016/C2015-0-04331-3). 